\title{
Knowledge of cardiovascular disease risk factors and practice of primary prevention of cardiovascular disease by Community Pharmacists in Nigeria: a cross-sectional study
}

\author{
Casmir E. Amadi ${ }^{1} \cdot$ Folasade O. Lawal $^{2} \cdot$ Amam C. Mbakwem $^{1} \cdot$ Jayne N. Ajuluchukwu $^{1} \cdot$ David A. Oke $^{1}$
}

Received: 27 April 2018 / Accepted: 22 October 2018 / Published online: 26 November 2018

(c) The Author(s) 2018

\begin{abstract}
Background Studies in international literature have shown that Community Pharmacists can make considerable impact in controlling cardiovascular disease risk factors, especially hypertension. In Nigeria, there are no studies on the knowledge of CVD risk factors by Community Pharmacists and their practice of primary prevention. Objective To assess the knowledge of CVD risk factors and practice of primary prevention of CVD amongst Nigerian community pharmacists. Setting Community Pharmacists in Lagos, Nigeria. Methods This cross-sectional study involved 168 Community Pharmacists. Their knowledge of CVD risk factors was assessed with the Heart Disease Fact Questionnaire. Their opportunistic screening practices for CVD risk factors (primary prevention) were also assessed. Main outcome measures Knowledge of CVD risk factors and practice of primary CVD prevention. Results The mean age of the participating pharmacists was $41.7( \pm 11.2)$ years and $87(51.8 \%)$ of them were males. The median number of years of practice was 9.0 (3-15) years. Mean knowledge score was 22.1 ( \pm 3.0$)$ with $154(91.7 \%)$ of the subjects scoring above $70 \%$. An average of $95.5 \%$ of the participants correctly identified hypertension, smoking, dyslipidaemia, obesity, physical inactivity and diabetes as CVD risk factors. Eighty-one (48.2\%) had good practice of primary CVD prevention. Conclusion: This study shows that Community Pharmacists in Nigeria have very good knowledge level of CVD risk factors and almost $50 \%$ of them practised primary prevention of CVD.
\end{abstract}

Keywords Community Pharmacists $\cdot$ CVD $\cdot$ Hypertension $\cdot$ Primary prevention $\cdot$ Nigeria

\section{Impacts on practice}

- Because the Nigerian pharmacists in Nigeria have a very good knowledge of cardiovascular risk factors and have the skills to practice primary prevention, it is possible to organise a pharmacists-led mass-screening for cardiovascular disease in Nigeria.

- Continuous training and support in knowledge of cardiovascular disease and prevention practice must be essential components of any government policy that seeks to improve the effectiveness of the primary prevention of CVD in Nigeria.

Casmir E. Amadi

acetalx@yahoo.com

1 Department of Medicine, College of Medicine, University of Lagos, Nigeria, Lagos, Nigeria

2 Victory Drugs Ltd, Festac, Lagos, Nigeria

\section{Introduction}

Cardiovascular disease (CVD) is a pre-eminent but preventable cause of death globally, accounting for an estimated $29 \%$ of all deaths [1]. The relative contribution of CVD to the burden of disease remains high in low, middle and high income countries of the world [1]. Interestingly over $80 \%$ of the global burden of CVD is borne by the Low and Middle Income Countries (LMICs) in the face of their traditional high prevalence of infectious diseases and poverty-related morbidities and mortalities, constituting a double burden of disease profile $[2,3]$. The rising prevalence of CVD in these LMICs is driven by rapid urbanization and its corollary of westernization of lifestyles viz increased consumption of saturated fats and sugars, high salt intake, increasing physical inactivity, smoking and unhealthy use of alcohol [4]. These risky behaviours predispose to the development of the metabolic risk factors for CVD such as obesity, hypertension, diabetes and dyslipidaemia [5]. In Nigeria CVD risk factors are highly prevalent. A recent meta-analysis showed 
that about $28.9 \%$ of adult Nigerians are hypertensive [6]. Similarly, the prevalence of diabetes is between 5 and $10 \%$ [7, 8] and dyslipidaemia 60.5\% [9]. Prevalence of obesity, smoking and sedentary living is on the increase also [9-11]. Research data provides evidence that there is a rising trend of CVD events and death across Nigeria [12, 13].

Cardiovascular disease is preventable through effective control and management of its risk factors. Data from researches provide sufficient evidence to suggest that the primary prevention of CVD represents a cost-effective approach to reducing this burden [14].

Because patients have difficulties accessing primary-care physicians and health-care costs are rapidly rising, greater use of community-based models of care has been proposed [15]. Among these models is the greater integration of the pharmacist as a provider of health services and member of the health-care team. Community pharmacists are highly accessible health-care professionals in most communities and have demonstrated an effective role in the management of several of these risk factors [16-18]. Their expertise in medicines management, adherence screening and management, and a growing role in health promotion has resulted in several studies demonstrating effective pharmacist involvement with multiple CVD risk factor management $[19,20]$.

With rising prevalence of CVD risk factors and CVD events and on a background of rising healthcare cost in Nigeria, Community Pharmacists may indeed have a role in stemming this tide. They, being community dwelling, are usually the first point of call for patients and appear more accessible and affordable to them. However, there is dearth of data on the knowledge and practice of primary prevention of CVD by this group of healthcare professionals in Nigeria.

\section{Aim of the study}

This study was designed to assess the knowledge of CVD risk factors and practice of primary prevention of CVD by Community Pharmacists in Lagos, Nigeria.

\section{Ethics approval}

Ethics approval for the study was obtained from the Health Research Ethics Committee of the Lagos University Teaching Hospital, Nigeria.

\section{Methods}

This was a cross sectional study. There were 800 registered Community Pharmacists in Lagos at the time of this study and they met monthly in twenty-two zones in the three senatorial districts of Lagos under the aegis of Lagos State Association of Community Pharmacists. Six zones (two from each of the three senatorial districts) were randomly selected for this study. The selection was based on the population density of the zones.

A sample size of 157 was calculated with the formula used when the survey population is less than 10,000 [21]. Allowing for an attrition rate of $20 \%$ the final sample size was 190. The leadership of the Association was approached for permission to carry out the study on their members. Their members were invited to participate in the study through a letter written by the researcher. The letter was read out to them by the Secretary of the Association in the plenary session of one of their monthly meetings, explaining the rationale for the study. To further enhance participation rate a copy of this letter was also pasted on the Association's Notice Boards in the six zones selected for the members to read. We aimed at recruiting 32 pharmacists from each of the six zones. One hundred and ninety pharmacists agreed to participate in the study but only 168 completed and returned their questionnaire giving a response rate of $88.4 \%$. Trained research personnel were used to administer a pretested, structured self-administered questionnaire to the consenting pharmacists during their monthly zonal meetings. Completing the questionnaire took an average of $20 \mathrm{~min}$. The entire period of the study lasted for 12 weeks. The questionnaire was initially pretested among a group of twenty Community Pharmacists in Lagos. Their responses were used to fine tune the final version used for the study.

The questionnaire consisted of four sections. Section one comprised the socio-demographic information of the participants while section two assessed their knowledge of CVD risk factors using the widely validated Heart Disease Fact Questionnaire (HDFQ). The HDFQ is a 25-item measure of heart disease knowledge which evaluates of knowledge of risk factors for heart disease, the link between diabetes and heart disease and how to reduce the risk of heart disease in the diabetic population [22, 23]. It has been used in other populations with reliable test-retest reliability, internal consistency and satisfactory discriminant validity [22] and has also been used among staff members of a university in Nigeria in 2015 [24]. Responses were 'True', 'false' or 'I don't know'. Scores were summed up and total score greater than 20 indicated good knowledge. Scores were also expressed in percentages. Score of $<50 \%$ was classified as low level of knowledge, between 50 and $69 \%$ as moderate level of knowledge and HDFQ score $>70 \%$ as good level of knowledge. Questions that less than $70 \%$ of the respondents answered correctly were deemed unsatisfactory. Section three assessed the participants' knowledge of the diagnostic cut-offs for hypertension, diabetes, dyslipidaemia and obesity while section four assessed their practice of primary prevention of CVD and comprised seven questions viz availability of functional sphygmomanometers, glucometers, routine 
measurement of blood pressure for their clients, routine measurement of $\mathrm{BMI} /$ waist circumference, awareness of any guidelines on hypertension, how frequently they advised their hypertensive and diabetic clients to check their cholesterol profile and how frequently they counselled their clients on healthy lifestyle choices in their Practices. Each of these questions was scored 1 point if the participant responded to them in the affirmative and zero if otherwise. Score $<2$ was regarded as poor practice, 3-4 as fair while greater than 4 as good. The questions in sections 3 and 4 were included to make the assessment of CVD knowledge more stringent and rigorous since the participants, being healthcare professionals, might find the HDFQ easier than the lay public whom it was originally designed for.

\section{Statistical analysis}

Data was analysed with SPSS software version 21.0. Numerical data was expressed as mean (SD) while categorical data was expressed as percentages. Chi-square test was used to compare proportions. A $p$ value $<0.05$ indicated statistical significance.

\section{Results}

\section{General characteristics of the subjects}

The mean age of the study population was $41.7( \pm 11.2)$ years while $87(51.8 \%)$ were males. The median number of years of practice was $9.0(3.0-15.0)$ years with $53(31.5 \%)$ having various postgraduate qualifications. Majority 87 (51.7\%) had their practices located in the urban areas. One hundred and fifty-six (92.8\%) saw at least 10 hypertensives monthly in their practices while $144(85.7 \%)$ and $85(50.6 \%)$ saw a minimum of 10 diabetics and smokers respectively every month in their practices. The rest of their general characteristics is shown in Table 1.

\section{Knowledge of CVD risk factors}

Stroke was correctly identified as an example of a CVD by $73(47.4 \%)$ of the respondents while the same number of respondents wrongly identified hypertension as a CVD. On the other hand 136 (81.4\%) of the pharmacists correctly identified smoking as a CVD risk factor. Table 2 shows the number of the participants who correctly identified the diagnostic cut-off points for hypertension,
Table 1 General characteristics of respondents

\begin{tabular}{|c|c|}
\hline Variable & Frequency $(\%)$ \\
\hline \multicolumn{2}{|c|}{ Age of respondents (years) } \\
\hline$\leq 30$ & $36(21.4)$ \\
\hline $31-45$ & $71(42.3)$ \\
\hline $46-60$ & $51(30.4)$ \\
\hline$>60$ & $10(6.0)$ \\
\hline \multicolumn{2}{|l|}{ Mean $( \pm$ SD $)$} \\
\hline \multicolumn{2}{|c|}{$41.73( \pm 11.2)$ years } \\
\hline \multicolumn{2}{|l|}{ Gender } \\
\hline Male & $87(51.8)$ \\
\hline Female & $81(48.2)$ \\
\hline \multicolumn{2}{|l|}{ Marital status } \\
\hline Single & $37(22.0)$ \\
\hline Married & $131(78.0)$ \\
\hline \multicolumn{2}{|c|}{ Additional qualification } \\
\hline None & $115(68.5)$ \\
\hline MSc & $20(11.9)$ \\
\hline Diploma/Cert & $14(8.3)$ \\
\hline Others & $19(11.3)$ \\
\hline \multicolumn{2}{|c|}{ Number of years of practice } \\
\hline$\leq 5$ & $64(38.1)$ \\
\hline $6-10$ & $35(20.8)$ \\
\hline$>10$ & $69(41.1)$ \\
\hline Median (Q1, Q3) & $9.0(3.0,15.0)$ \\
\hline \multicolumn{2}{|l|}{ Location of practice } \\
\hline Urban & $86(51.2)$ \\
\hline Semi/urban & $73(43.4)$ \\
\hline Rural & $9(5.4)$ \\
\hline \multicolumn{2}{|c|}{ Average number of hypertensives seen per month } \\
\hline$<10$ & $12(7.1)$ \\
\hline $10-20$ & $44(26.2)$ \\
\hline$>20$ & $112(66.7)$ \\
\hline \multicolumn{2}{|c|}{ Average number of diabetics seen per month } \\
\hline$<10$ & $24(14.3)$ \\
\hline $11-20$ & $72(42.9)$ \\
\hline$>20$ & $72(42.9)$ \\
\hline \multicolumn{2}{|c|}{ Number of smokers seen per month } \\
\hline$<10$ & $83(49.4)$ \\
\hline $10-20$ & $62(36.9)$ \\
\hline$>20$ & $23(13.7)$ \\
\hline
\end{tabular}

diabetes, obesity with BMI, abdominal obesity and treatable dyslipidaemia.

\section{Assessment of knowledge of CVD risk factors}

Figure 1 shows the frequency scores of the HDFQ while Table 3 shows the responses of the participants to the items on the HDFQ. About $95.5 \%$ of the participants could identify the traditional risk factors for CVD viz 
Table 2 Knowledge of diagnostic cut-off for common CVD risk factors

\begin{tabular}{|c|c|c|}
\hline Risk factor & Cut-off & Frequency $(\%)$ \\
\hline \multirow[t]{5}{*}{ Hypertension } & ${ }^{\mathrm{a}} \mathrm{BP} \geq 140 / 90 \mathrm{mmHg}$ & $97(57.7)$ \\
\hline & $\mathrm{BP}>130 / 95 \mathrm{mmHg}$ & $19(11.3)$ \\
\hline & $\mathrm{BP}>120 / 80 \mathrm{mmHg}$ & $37(22.0)$ \\
\hline & $\mathrm{BP}>150 / 90 \mathrm{mmHg}$ & $1(0.6)$ \\
\hline & Unknown & $14(8.3)$ \\
\hline \multirow[t]{4}{*}{ Diabetes } & ${ }^{\mathrm{a}} \mathrm{FBS} \geq 126 \mathrm{mg} / \mathrm{dl}$ & $53(31.5)$ \\
\hline & $\mathrm{FBS}>140 \mathrm{mg} / \mathrm{dl}$ & $23(13.7)$ \\
\hline & $\mathrm{FBS}>110 \mathrm{mg} / \mathrm{dl}$ & 67 (39.9) \\
\hline & Unknown & $25(14.9)$ \\
\hline \multirow[t]{4}{*}{ Obesity } & ${ }^{\mathrm{a}} \mathrm{BMI} \geq 30 \mathrm{~kg} / \mathrm{m}^{2}$ & $43(25.6)$ \\
\hline & $\mathrm{BMI}>35 \mathrm{~kg} / \mathrm{m}^{2}$ & $32(19.0)$ \\
\hline & $\mathrm{BMI}>25 \mathrm{~kg} / \mathrm{m}^{2}$ & $52(31.0)$ \\
\hline & Unknown & $41(24.4)$ \\
\hline \multirow[t]{4}{*}{ Abdominal obesity (male) } & ${ }^{\mathrm{a}} \mathrm{WC}>102 \mathrm{~cm}$ & $38(22.6)$ \\
\hline & $>88 \mathrm{~cm}$ & $14(8.3)$ \\
\hline & $>90 \mathrm{~cm}$ & $32(19.0)$ \\
\hline & Unknown & $84(50.0)$ \\
\hline \multirow[t]{4}{*}{ Abdominal obesity (female) } & $>102 \mathrm{~cm}$ & $20(11.9)$ \\
\hline & ${ }^{\mathrm{a}}>88 \mathrm{~cm}$ & $43(25.6)$ \\
\hline & $>90 \mathrm{~cm}$ & $17(10.1)$ \\
\hline & Unknown & $88(52.4)$ \\
\hline \multirow[t]{5}{*}{ Hypercholesterolaemia } & ${ }^{\mathrm{a}} \mathrm{Tc} \geq 240 \mathrm{mg} / \mathrm{dl}$ & $22(13.1)$ \\
\hline & Tc $220 \mathrm{mg} / \mathrm{dl}$ & $18(10.7)$ \\
\hline & $\mathrm{Tc} 200 \mathrm{mg} / \mathrm{dl}$ & $37(22.0)$ \\
\hline & Tc $190 \mathrm{mg} / \mathrm{dl}$ & $15(8.9)$ \\
\hline & Unknown & $76(45.2)$ \\
\hline
\end{tabular}

$B P$ blood pressure, $F B G$ fasting blood glucose, BMI Body Mass Index, $W C$ waist circumference, $T c$ total cholesterol

${ }^{\mathrm{a}}$ Correct answer

hypertension (97.6\%), smoking (97\%), dyslipidaemia (97\%), obesity (96.4\%), physical inactivity (95.2\%) and diabetes $(91.7 \%)$, indicating high knowledge. They were also very knowledgeable of the impact of managing/controlling these risk factors in the development of heart disease and the relationship between diabetes and other CVD risk factors as they affect the risk of development of heart disease. However, participants displayed low knowledge of level High Density Lipoprotein cholesterol (HDL-c) in diabetes and females with diabetes having a higher risk of development of heart disease. Table 4 shows the association between the HDFQ scores and some of the sociodemographic characteristics of the participants. There was no relationship between age, gender, location of practice, duration of practice, possession of additional qualifications with HDFQ scores. Figure 2 shows the linear relationship between the HDFQ scores and knowledge of the diagnostic cut-offs for the CVD risk factors. The higher the HDFQ

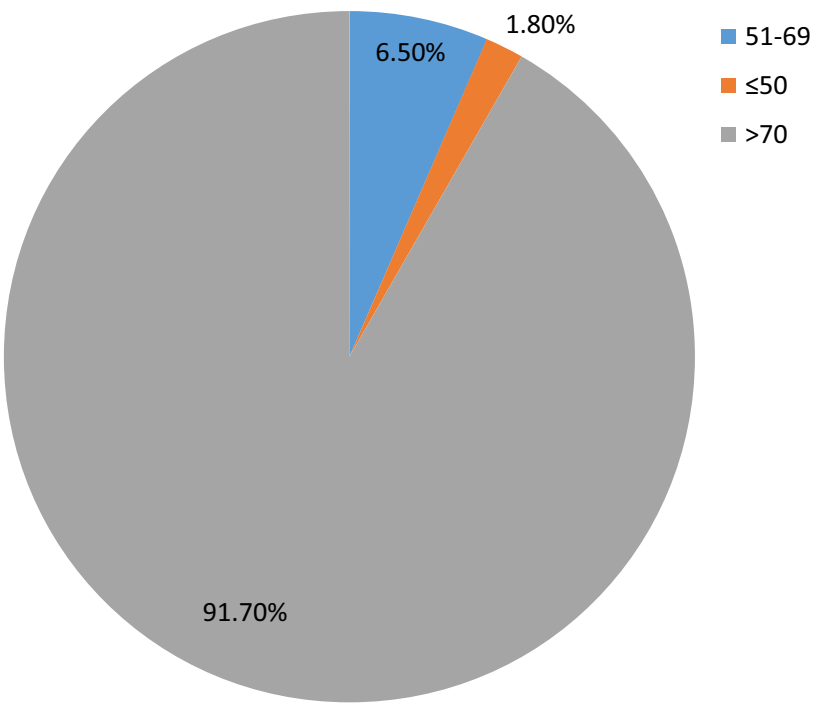

Fig. 1 Pie chart showing the distribution of the HDFQ scores of the respondents

scores the more likely the pharmacists would correctly identify the diagnostic cut off $(p=0.045)$.

\section{Practice of primary prevention of CVD}

One hundred and sixty of the pharmacists (95.2\%) indicated that they had functional sphygmomanometers while $139(82.7 \%)$ routinely measured the blood pressure of most clients who consulted them for a broad range of reasons. Details of pharmacists' practice of primary prevention of CVD are shown in Table 5. With regards to knowledge of any guidelines for hypertension $73(43.4 \%)$ were aware of the existence of guidelines on hypertension but none was able to mention any including the JNC VII guideline, which was the operational hypertension guideline in Nigeria as at the time of this study. Figure 3 the shows frequency of the scores on the practice of primary prevention of CVD. Eighty-one (48.2\%) of them had good primary CVD prevention practice score. Table 6 shows an association between the HDFQ scores and practice of primary prevention of CVD. Those with HDFQ scores greater than $70 \%$ had higher primary CVD prevention scores $(p=0.026)$.

\section{Discussion}

This study, first of its kind in Nigeria (to the best knowledge of the authors), shows that Community Pharmacists in Lagos, Nigeria have very good knowledge of CVD risk factors using the HDFQ instrument. This contrasts with the findings from a similar study done amongst staff members of a tertiary institution in South West Nigeria where $19.9 \%$ 
Table 3 Correct responses to HDFQ questionnaire

\begin{tabular}{|c|c|}
\hline Questions & Frequency $(\%)$ \\
\hline A person always knows when they have heart disease & $142(84.5)$ \\
\hline If someone has a family history of heart disease, he/she is at risk for developing heart disease & $157(93.5)$ \\
\hline The older a person is, the greater their risk of having heart disease & $151(89.9)$ \\
\hline Smoking is a risk factor for heart disease & $163(97.0)$ \\
\hline A person who stops smoking will lower their risk of heart disease & $159(94.6)$ \\
\hline High blood pressure is a risk factor for heart disease & $164(97.6)$ \\
\hline Keeping blood pressure under control will reduce a person's risk for developing heart disease & $162(96.4)$ \\
\hline High cholesterol is a risk factor for developing heart disease & $163(97.0)$ \\
\hline Eating fatty foods does not affect blood cholesterol & $157(93.5)$ \\
\hline If someone's good cholesterol (HDL) is high he/she is at risk for heart disease & $138(82.1)$ \\
\hline If someone's bad cholesterol (LDL) is high he/she is at risk for heart disease & $155(92.3)$ \\
\hline Being overweight increases a person's risk for heart disease & $162(96.4)$ \\
\hline Regular physical activity will lower a person's chance of getting heart disease & $160(95.2)$ \\
\hline Only exercising at a gym or in an exercise class will lower a person's chance of developing heart disease & $146(86.9)$ \\
\hline Walking and gardening are considered exercise that will help lower a person's chance of developing heart disease & $140(83.3)$ \\
\hline Diabetes is a risk factor for developing heart disease & $154(91.7)$ \\
\hline High blood sugar puts a strain on the heart & $131(78.0)$ \\
\hline $\begin{array}{l}\text { If someone's blood sugar is high over several months it can cause his/her cholesterol level to go up and increase his/her risk of } \\
\text { heart disease }\end{array}$ & $108(64.3)$ \\
\hline $\begin{array}{l}\text { A person who has diabetes can reduce his/her risk of developing heart disease if he/she keeps his/her blood sugar level under } \\
\text { control }\end{array}$ & $153(91.1)$ \\
\hline Person with diabetes rarely have high cholesterol & $130(77.4)$ \\
\hline If a person has diabetes, keeping his/her cholesterol under control will help lower his/her chance of having heart disease & $145(86.3)$ \\
\hline People with diabetes tend to have low HDL (good) cholesterol & $49(29.2)$ \\
\hline $\begin{array}{l}\text { A person who has diabetes can reduce his/her risk of developing heart disease if he/she keeps his/her blood pressure under } \\
\text { control }\end{array}$ & $150(89.3)$ \\
\hline A person who has diabetes can reduce his/her risk of developing heart disease if he/she keeps his/her weight under control & $153(91.1)$ \\
\hline Men with diabetes have a higher risk of heart disease than women with diabetes & $37(22.0)$ \\
\hline
\end{tabular}

of the participants had good knowledge of CVD risk factors [24]. Wagner et al. [23], using the same instrument, also demonstrated low knowledge of CVD risk in a population of Spanish speaking diabetics in Puerto Rico. The higher level of knowledge observed in our study was not surprising since the studied population comprised healthcare professionals who should be knowledgeable about CVD. In our study the knowledge of these risk factors was independent of age, gender, location of practice, duration of practice and possession of additional qualifications and corroborates findings from similar studies $[23,24]$. This high level of knowledge displayed by the participants in this study may provide a basis for a feasibility study on the effectiveness of Community Pharmacists in CVD risk factor screening in Nigeria.

Our study further demonstrated that the participants displayed good knowledge of both the behavioural (physical inactivity, smoking and unhealthy diets) and biologic (hypertension, diabetes, obesity and dyslipidaemia) risk factors for CVD. However in relative terms knowledge of diabetes and measures of obesity was lower. This was reflected in the lower of number of participants who correctly identified the diagnostic cut-offs for diabetes and abdominal obesity compared to hypertension and also the lower number of participants who screened clients for diabetes and obesity in their practices compared to hypertension. The reason for this might be might be due to the higher prevalence of hypertension compared to diabetes in the general Nigerian population $[6,8]$. Secondly the invasive nature of screening for diabetes with a glucometer could be a demotivation for them and their clients. For obesity the technicalities for measuring parameters for obesity (waist circumference and body mass index) accurately may be exerting on the pharmacists in addition to time and space constraints. These may discourage them from screening for obesity. A similar study in Australia found availability of space a determinant of screening for obesity [25].

Our study also found that majority of the pharmacists were involved in primary prevention of CVD through screening for risk factors and counselling on the importance of healthy lifestyle choices. Hypertension screening was more commonly done than for diabetes and obesity. This might also be explained by the reasons adduced 
Table 4 Association between HDFQ score category and socio-demographic characteristics
Fig. 2 Scatter plot showing the relationship between HDFQ scores and knowledge of diagnostic cut off for common CVD risk factors. Spearman correlation coefficient: 0.317 ; $p=0.045$

\begin{tabular}{|c|c|c|c|c|}
\hline \multirow[t]{2}{*}{ Characteristics } & \multicolumn{2}{|c|}{ HDFQ score category } & \multirow[t]{2}{*}{$\mathrm{X}^{2}$} & \multirow[t]{2}{*}{$p$ value } \\
\hline & $>70$ & $\leq 70$ & & \\
\hline Age of respondents (years) & & & 2.184 & 0.534 \\
\hline$\leq 30$ & $31(86.1)$ & $5(13.9)$ & & \\
\hline $31-45$ & $67(94.4)$ & $4(5.6)$ & & \\
\hline $46-60$ & $47(92.2)$ & $4(7.8)$ & & \\
\hline$>60$ & $9(90.0)$ & $1(10.0)$ & & \\
\hline Gender & & & 0.176 & 0.675 \\
\hline Male & $79(90.9)$ & $8(9.2)$ & & \\
\hline Female & $75(92.6)$ & $6(7.4)$ & & \\
\hline Marital status & & & 0.003 & 0.955 \\
\hline Single & $34(91.9)$ & $3(8.1)$ & & \\
\hline Married & $120(91.6)$ & $11(8.4)$ & & \\
\hline Additional qualification & & & 1.127 & 0.771 \\
\hline None & $107(93.0)$ & $8(7.0)$ & & \\
\hline MSc & $18(90.0)$ & $2(10.0)$ & & \\
\hline Diploma/Cert & $12(85.7)$ & $2(14.3)$ & & \\
\hline Others & $17(89.5)$ & $2(10.0)$ & & \\
\hline Number of years of practice & & & 1.111 & 0.574 \\
\hline$\leq 5$ & $58(90.6)$ & $6(9.4)$ & & \\
\hline $6-10$ & $31(88.6)$ & $4(11.4)$ & & \\
\hline$>10$ & $65(94.2)$ & $4(5.8)$ & & \\
\hline Median (Q1, Q3) & $9.0(3.0,15.3)$ & $6.0(1.8,14.8)$ & & \\
\hline Location of practice & & & 5.096 & 0.078 \\
\hline Urban & $82(95.3)$ & $4(4.7)$ & & \\
\hline Semi/urban & $63(86.3)$ & $10(13.7)$ & & \\
\hline Rural & $8(100.0)$ & $0(0.0)$ & & \\
\hline
\end{tabular}

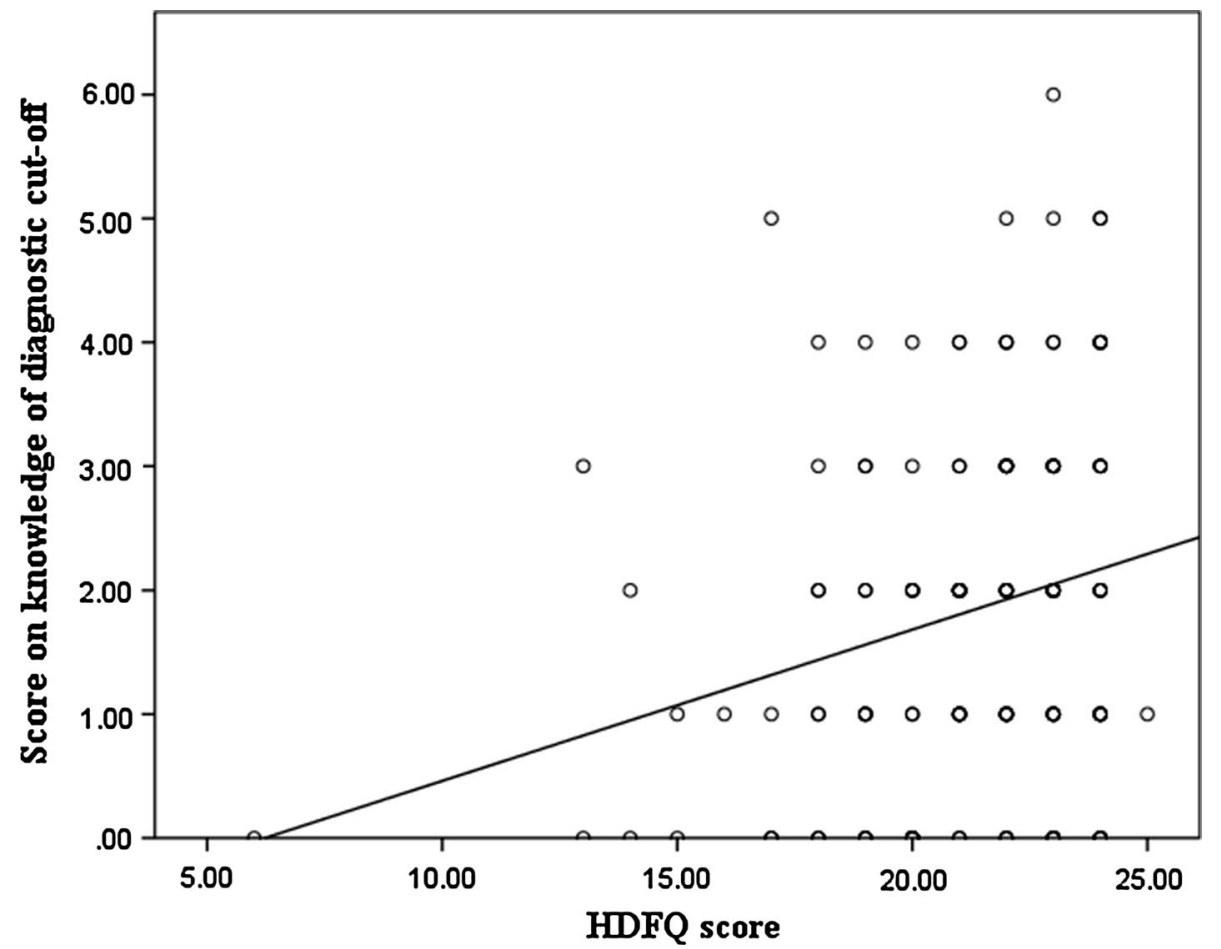


Table 5 Practice Primary Prevention of CVD among the Respondents

\begin{tabular}{|c|c|c|}
\hline Practice & Frequency & Percentage \\
\hline $\begin{array}{l}\text { Availability Functional BP Sphygmoma- } \\
\text { nometers }\end{array}$ & 160 & 95.2 \\
\hline $\begin{array}{l}\text { Routinely measure the BP of hypertensive } \\
\text { client }\end{array}$ & 139 & 82.7 \\
\hline $\begin{array}{l}\text { Functional glucometer to measure blood } \\
\text { glucose }\end{array}$ & 122 & 72.6 \\
\hline $\begin{array}{l}\text { Routinely measure BMI/waist circumfer- } \\
\text { ence }\end{array}$ & 48 & 28.6 \\
\hline Awareness of guideline on hypertension & 73 & 43.5 \\
\hline \multicolumn{3}{|c|}{$\begin{array}{l}\text { Frequency of informing hypertensives or diabetics to check their } \\
\text { cholesterol level }\end{array}$} \\
\hline Very often & 84 & 50.0 \\
\hline Sometimes & 54 & 32.1 \\
\hline Rarely & 20 & 11.9 \\
\hline Never & 10 & 6.0 \\
\hline \multicolumn{3}{|c|}{$\begin{array}{l}\text { Frequency of advising hypertensives or diabetics on lifestyle man- } \\
\text { agement }\end{array}$} \\
\hline Very often & 116 & 69.0 \\
\hline Sometimes & 38 & 22.6 \\
\hline Rarely & 4 & 2.4 \\
\hline Never & 10 & 6.0 \\
\hline
\end{tabular}

above. Joyce et al. [25], studying the practice of primary prevention of CVD among Community Pharmacists in Australia, found that hypertension was the most commonly screened risk factor, similar to what our study demonstrated.
Studies from various parts of the world have documented the feasibility of using Community Pharmacists in CVD screening in their practices [26-28]. These screening programmes were mostly opportunistic in nature and involved both healthy and ill individuals. This feasibility compares well with studies that have demonstrated the feasibility of CVD screening by other health professionals [29, 30]. Some of these screening efforts reported prevalence of CVD risk factors similar to national prevalence and were also able to detect previously undiagnosed risk factors [28, 31]. Rohla et al. [31], in a cross-sectional study involving 184 pharmacies in Lower Austria, found an overall prevalence of CVD risk factors similar to reported prevalence in national surveys with about $30 \%$ of the cases being newly diagnosed. In addition public uptake of these screening programmes was positive $[32,33]$. Furthermore in some of these studies identified cases were referred to the physicians for further evaluation and definitive management suggesting possible opportunities for a collaborative care model involving the physicians and the pharmacists $[28,31]$. In summary, these studies demonstrate that CVD screening by Community Pharmacists is feasible, accessible and acceptable to the public and might be an effective alternative to public screening.

The success recorded above may be attributable to a host of factors. First, Community Pharmacists are located within the community and thus are usually the first point of contact and in some cases the only point of contact for patients seeking the services of a health-care provider without an appointment [18, 34]. In addition, they have extended hours of service which further increases accessibility to care.
Fig. 3 Bar chart showing scores on the practice of primary prevention of CVD among the participants

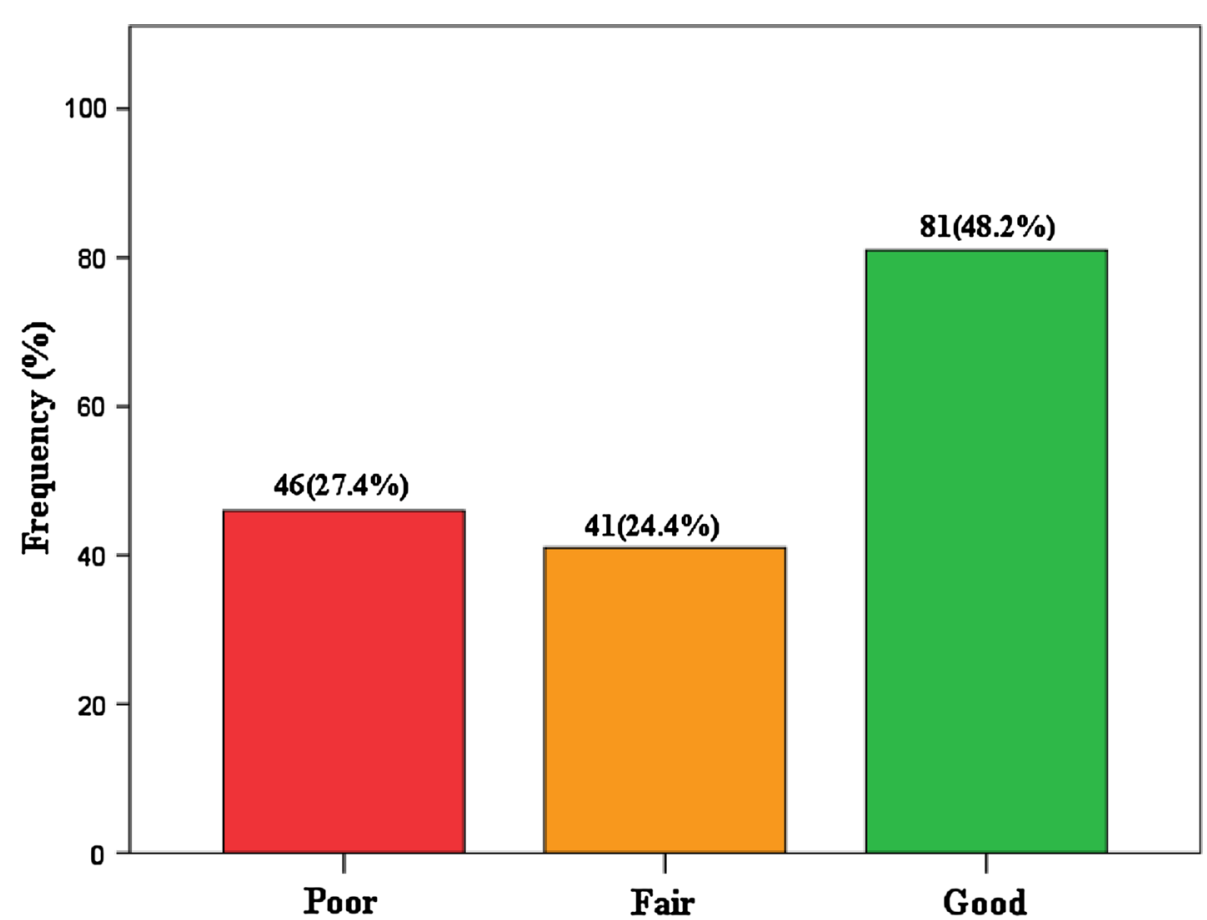


Table 6 Association between HDFQ score grade and primary prevention practices

\begin{tabular}{|c|c|c|c|c|}
\hline \multirow{2}{*}{$\begin{array}{l}\text { Primary preven- } \\
\text { tion practice }\end{array}$} & \multicolumn{2}{|c|}{ HDFQ Score grade } & \multirow[t]{2}{*}{$X^{2}$} & \multirow[t]{2}{*}{ p-value } \\
\hline & $>70$ & $\leq 70$ & & \\
\hline Poor & 38 (82.6) & $8(17.3)$ & 7.269 & $0.026^{*}$ \\
\hline Fair & 38 (92.7) & $3(7.3)$ & & \\
\hline Good & 78 (93.3) & $3(3.7)$ & & \\
\hline
\end{tabular}

*Significant

Being community dwelling, they build informal and genial relationships with members of their host communities, engendering their trust and loyalty. This places them in a vintage position to implement primary prevention strategies for CVD and collaborate with the physician in ensuring continuity of care $[18,34]$. In some settings healthcare delivery service by them appears relatively cheaper and more cost effective for the patient [34].

Despite these benefits, some factors have been identified that could potentially hinder the ability and effectiveness of Community Pharmacists in CVD screening. In climes where pharmacists have been involved in CVD screening some barriers have been identified that limit their effectiveness. These include time constraints, limited physical space to ensure privacy of the patients, need for further training, lack of regulatory policy, remuneration and reimbursement mechanisms and poor uptake of CVD screening services by the public [33, 35-37]. In Nigeria government policy integrating Community Pharmacists fully into the nation's healthcare delivery system is apparently lacking. They operate primarily as private commercial ventures offering pharmaceutical services that complement the government's healthcare system. In the absence of a government policy, training and certifying them to render CVD care delivery remains impracticable. By extension the expected collaborative linkage between them and physicians will at best be weak as they would be seen to be offering these services outside the ambit of government policy. This could also affect the public's confidence in the uptake of such services. Time management constraints, lack of space, lack of training and lack of reimbursements might be potential impediments as in other climes. Most community pharmacies in Nigeria are sole proprietorships, driven by profit. Introduction of CVD care delivery services that will involve personal training to improve competencies, time and physical space resources and which are not recognised by the government nor covered by any reimbursement schemes of the National Health Insurance Program and which the patients may be unwilling to pay for might not be commercially appealing to them and may likely discourage them from venturing into such. Further, there is the issue of perceived 'turf encroachment', whereby pharmacists are perceived or act to supplant the role of physicians and compete rather than collaborate with them. This has been reported as another major impediment to the incorporation of pharmacists in mainstream CVD care [18]. In Nigeria, inter-professional rivalry in the health sector is rife, leading to frequent industrial disharmony and friction between the other health workers on one hand and the physicians on the other hand. The issue of 'turf encroachment' will be a major consideration in any collaborative healthcare delivery model that will involve the physician and the pharmacist as the latter might rightly or otherwise be seen to usurp or compete rather collaborate with the former. Issues such as 'ownership of patients' and remuneration structure might be potential sources of conflicts should this collaboration become operational. This scenario would be made worse in the absence of a government policy and operational guidelines. These are serious issues that may hinder the effectiveness of these health professionals in CVD screening services.

\section{Limitations}

This study has some limitations. The HDFQ used in this study was designed for assessment of knowledge of CVD risk factors in the lay public. Our study population comprised Community Pharmacists who are highly trained healthcare professionals. Thus results from the HDFQ are subject to bias. Secondly some of the questions involved self-report, which could have also introduced recall bias. The size of the population studied was small and this might have affected the results and the conclusions.

\section{Conclusions}

Our study has shown that Community Pharmacists in Nigeria have very good knowledge of CVD risk factors and also practice primary prevention of CVD. Thus assessment of the feasibility of using them for CVD risk factor screening is possible if enabling factors are in place. However, their knowledge of diabetes and obesity needs to be deepened. For them to be effective in the provision of these screening services there should a government policy that will regulate their training, certification, practice for CVD screening and as well as provide a framework of incentivising this service.

Funding None.

Conflicts of interest None.

Open Access This article is distributed under the terms of the Creative Commons Attribution 4.0 International License (http://creativeco mmons.org/licenses/by/4.0/), which permits unrestricted use, distribution, and reproduction in any medium, provided you give appropriate 
credit to the original author(s) and the source, provide a link to the Creative Commons license, and indicate if changes were made.

\section{References}

1. World Health Organization. Prevention of cardiovascular disease: guidelines for assessment and management of cardiovascular risk. Geneva, Switzerland; 2007. Accessed 22 July 2015.

2. Lopez AD, Mathers CD, Ezzati M, Jamison DT, Murray CJ. Global and regional burden of disease and risk factors, 2001: systematic analysis of population health data. Lancet. 2006;367(9524):1747-57.

3. Bygbjerg IC. Double burden of non-communicable and infectious diseases in developing countries. Science. 2012;337(6101):1499-501.

4. Yusuf S, Reddy S, Ounpuu S, Anand S. Global burden of cardiovascular diseases: part II. Variation in cardiovascular diseases by specific ethnic groups and geographic regions and preventive strategies. Circulation. 2001;104(23):2855-64.

5. Steyn K, Sliwa K, Hawken S, Commerford P, Onen C. Risk factors associated with myocardial infarction in Africa: the INTERHEART Africa Study. Circulation. 2005;112:3554-61.

6. Adeloye D, Basquill C, Aderemi AV, et al. An estimate of the prevalence of hypertension in Nigeria: a systematic review and meta-analysis. J Hypertens. 2015;33(2):230-42.

7. International Diabetes Federation. 6th ed. 2013. p. 23-6. https:// www.idf.org/e-library/epidemiology-research/diabetes-atlas/19atlas-6th-edition.html. Accessed 17 Nov 2018.

8. Ogbera OA, Ekpebegh C. Diabetes mellitus in Nigeria: the past, present and future. World J Diabetes. 2014;5(6):905-11.

9. Odeyemi KA, Osibogun A, Akinsele AO, Sadiq L. The prevalence and predictors of cigarette smoking in secondary students in Nigeria. Niger Postgrad Med J. 2009;16:40-5.

10. Akaralo-Anthony SN, Adebamowo CA. Prevalence and correlates of leisure-time physical activity among Nigerians. BMC Public Health. 2014;14:529.

11. World Health Organization. Global strategy on diet, physical activity \& health. 2004. http://www.who.int/nmh/wha/59/dpas/ en/. Accessed 17 Nov 2018.

12. Ogundamola OJ, Oladosun OY. Pattern and outcomes of admissions in the medical wards of a tertiary health centre in a rural community of Ekiti State, Nigeria. Ann Afr Med. 2014;13:195-203.

13. Oguanobi NI, Ejim EC, Onwubere BJ, Ike SO, Anisiuba BC, Ikeh VO, Aneke EO. Pattern of cardiovascular disease amongst medical admissions in a regional teaching hospital in South-eastern Nigeria. Niger J Cardiol. 2013;10:77-80.

14. Schwappach D, Boluarte T, Suhrcke M. The economics of primary prevention of cardiovascular disease-a systematic review of economic evaluations. Cost Eff Resour Alloc. 2007;5(1):5.

15. Ferdinand KC, Patterson KP, Taylor C, Fergus IV, Nasser SA. Community-based approaches to prevention and management of hypertension and cardiovascular disease. J Clin Hypertens (Greenwich). 2012;14:336-43.

16. Machado M, Bajcar J, Guzzo GC, Einarson TR. Sensitivity of patient outcomes to pharmacist interventions. Part II: systematic review and meta-analysis in hypertension management. Ann Pharmacother. 2007;41(11):1770-81.

17. Blenkinsopp A, Anderson C, Armstrong M. Systematic review of the effectiveness of community pharmacy-based interventions to reduce risk behaviours and risk factors for coronary heart disease. J Public Health. 2003;25(2):144-53.
18. Morgado M, Rolo S, Castelo-Branco M. Pharmacist intervention to enhance hypertension control: a randomised controlled trial. Int J Clin Pharm. 2011;33(1):132-40.

19. George J, McNamara GJ, Stewart K. The roles of community pharmacists in cardiovascular disease prevention and management. AMJ. 2011;4(5):266-72.

20. Santschi VS, Colosimo AL, Chilero A, Burnand B, Paradis G. Pharmacists interventions to improve cardiovascular risk factors in diabetes. a systematic review and meta-analysis. Diabetes Care. 2012;35:2706-17.

21. Araoye MO. Sample size determination. In: Research methodology with statistics for health and social sciences. 1st Ed. Ilorin: Nathadex Publishers; 2004. p. 115-20.

22. Wagner J, Lacey K, Chyun D, Abbot D. Development of a questionnaire to measure heart disease risk knowledge in people with diabetes. The Heart Disease Facts Questionnaire. Patient Educ Couns. 2005;58:82-7.

23. Wagner J, Lacey K, Chyun D, Abbot D. Knowledge of heart disease risks among Spanish speakers with diabetes. The role of interpreters in the medical encounter. Ethn Dis. 2005;15:679-84.

24. Akintunde AA, Akintunde TS, Opadijo OG. Knowledge of heart disease risk factors among workers in a Nigerian University. A call for concern. Niger Med J. 2015;56(2):91-5.

25. Joyce A, Berbatis C, Sunderland VB. Analysis of primary prevention services for cardiovascular disease in Australia's community pharmacies. Aust N Z J Public Health. 2007;31:516-9.

26. Jahangard-Rafsanjani Z, Hakimzadeh N, Sarayani A, Najafi S, Heidari K, Javadi MR, Hadjibabaie M, Gholami K. A community pharmacy-based cardiovascular risk screening service implemented in Iran. Pharm Pract. 2017;15(2):919-25.

27. Via-Sosa MA, Toro C, Trave P, March MA. Screening premorbid metabolic syndrome in community pharmacies: a cross-sectional descriptive study. BMC Public Health. 2014;14:487.

28. Willis A, Rivers P, Gray LJ, Davies M, Khunti K. The effectiveness of screening for diabetes and cardiovascular disease risk factors in a community pharmacy setting. PLoS ONE. 2014;9(4):e91157.

29. Horgan JMP, Blenkinsopp A, McManus RJ. Evaluation of cardiovascular opportunistic risk assessment pilot ('Heart MOT' service) in community pharmacies. J Public Health. 2010;32(1):110-6.

30. O'Donovan DO, Byre S, Sahm LJ. Pharmacists use of screening tools to estimate risk of CVD: a review of the literature. Pharmacy. 2014;2:27-39.

31. Rohla M, Haberfeld $\mathrm{H}$, Sinzinger $\mathrm{H}$, et al. Systematic screening for cardiovascular risk in pharmacies. Open Heart. 2016;3:e000497.

32. Taylor J, Krska J, Mackridge A. A community pharmacy-based cardio-vascular screening service: views of service users and the public. Int J Pharm Pract. 2012;20:277-84.

33. Hindi AMK, Schafheutle EI, Jacobs S. Patients and public perspectives of community pharmacies in the UK: a systematic review. Health Expect. 2018;21:409-28.

34. Chiazor EI, Evans M, van Worden H, Oparah AC. A systematic review of community pharmacists' interventions in reducing major risk factors for cardiovascular disease. J Value Health Reg Issues. 2015;7c:9-21.

35. Jahangard-Rafsanjani Z, Sarayani A, Javadi MR, Hadjibabaie M, Rashidian A, Ahmadvand A, et al. Pharmacists' attitudes and perceived barriers about community pharmacy-based cardiovascular risk screening services. J Pharm Care. 2014;2(4):142-8.

36. Kotecki JE, Elanjian SI, Torabi MR. Health promotion beliefs and practices amongst pharmacists. J Am Pharm Asso. 2000;40:773-9.

37. Uema SA, Vega EM, Armando PD, Fontana D. Barriers to pharmaceutical care in Argentina. Pharm World Sci. 2008;30:211-5. 